\title{
Phase Transformation Introduced by Mechanical and Chemical Surface Preparations of Tetragonal Zirconia Polycrystals
}

\author{
Nibedita Mitra, ${ }^{*}$ Kalyani Vijayan, ${ }^{\dagger}$ B. N. Pramila Bai, ${ }^{*}$ and S. K. Biswas* \\ Department of Mechanical Engineering, Indian Institute of Science, Bangatore, India \\ Materials Science Division, National Aeronautical Laboratory, Bangalore, India
}

inting of $\mathrm{Y}_{2} \mathrm{O}_{3}$-doped TZP rods by a low-speed diamond JW introduces an unidentified, metastable phase $X$ r. $\left.\mathrm{ZrO} \mathrm{O}_{2}\right)$ coexisting with the tetragonal $\left(t-\mathrm{ZrO}_{2}\right)$ and the sonoclinic $\left(m-\mathrm{ZrO}_{2}\right)$ phases initially present in the sample. iurther mechanical deformation of the cut surface by ndentation or polishing sustains the $x-\mathrm{ZrO}_{2}$. Chemical sching removes the $x-\mathrm{ZrO}_{2}$ and increases the $m-\mathrm{ZrO}_{2}$ ontent.

\section{Introduction}

THE phase transformation from tetragonal to monoclinic structure in $\mathrm{ZrO}_{2}$ can be induced by mechanical stresses' ind thermal effects. ${ }^{2}$ While there is an established notion that tis transformation is martensitic, ${ }^{3}$ some recent work on Y-TZP hows that the transformation may be isothermal and bainitic in ature. ${ }^{4}$

Most materials require mechanical and/or chemical surface reparation to render them useful for engineering applications. the present paper reports a preliminary study of the structural hanges brought about by a cutting process and subsequent rechanical and chemical treatments of the cut surface.

\section{Experimental Procedure}

3Y-TZP rods, $5.6 \mathrm{~mm}$ in diameter (obtained from $\mathrm{M} / \mathrm{s} \mathrm{CVC}$ cientific Products Ltd., U.K.) were cut by a low-speed saw Buehler, Lake Bluff, IL) incorporated with a 0.3 -mm-thick lamond wafering blade, under a load of $2 \mathrm{~N}$ at $175 \mathrm{rpm}$ using noil-based lubricant. The cut surfaces were subjected to three ifferent treatments: (i) polishing - using a 3- $\mu \mathrm{m}$ diamond aste; (ii) indentation-21 indents of 70- $\mu \mathrm{m}$ depth made using $120^{\circ}$ included angle cone indenter, and (iii) etching - in boilng orthophosphoric acid for $0.75,2$, and $3 \mathrm{~min}$.

$\mathrm{X}$-ray diffraction (XRD) patterns were recorded using $\mathrm{CuK \alpha}$ adiation in powder diffractometer with a monochromator in the iffracted beam and a proportional counter. Sample rotation peed and the chart speed were $1 / 4^{\circ}$ and $10 \mathrm{~mm} / \mathrm{min}$, respecively. For profile fitting, point-counted intensity data were colected at $2 \theta$ intervals of $0.02^{\circ}$.

\section{Results and Discussion}

Figure 1(A) shows part of the XRD pattern recorded from the irgin surface of an as-received 3Y-TZP rod. The sample is redominantly tetragonal. The presence of a small fraction of $\mathrm{HrO}_{2}$ is revealed by the occurrence of reflections at $2 \theta \approx$ $28.5^{\circ}$ and $31.5^{\circ}$. The volume fraction of the monoclinic phase, $v_{M}$, estimated from the relation ${ }^{\varsigma}$

$$
v_{\mathrm{M}}=\frac{I(\overline{I I I})_{\mathrm{M}}+I(I 11)_{\mathrm{M}}}{I(\bar{I} 11)_{\mathrm{M}}+I(I 11)_{\mathrm{M}}+I(I I I)_{\mathrm{T}}}
$$

is $\sim 0.2$. In Eq. (1) the $I(h k l)$ 's represent the integrated intensities, $I_{\text {iths }}$, corrected for Lorentz polarization (Lp), multiplicity $(m)$, and thermal vibrations $(B)$, and normalized with respect to $\Sigma f_{1}^{2}$, where the $f_{1}$ 's correspond to the atomic scattering factors of the zirconium and the oxygen atoms:

$$
I(\mathrm{hkl})=I_{\text {oths }} \frac{1}{\mathrm{Lp}} \frac{1}{m} \frac{1}{\Sigma f_{1}^{2} e^{-2 B \sin ^{2} \theta \lambda^{2} \lambda^{2}}}
$$

The temperature factors $B_{7 \mathrm{Zr}}$ and $B_{0}$ used in Eq. (2) are 1.66 and $3.11 \dot{\mathrm{A}}^{2}$, respectively. ${ }^{6} \theta$ and $\lambda$ correspond to the Bragg angle of the reflection $(h k l)$ and the wavelength of the radiation, respectively.

Cutting of the rods introduces a shoulder (Fig. 1(B)) on the low-angle side of the most intense $t-\mathrm{ZrO}_{2}$ reflection, $(111)_{\mathrm{T}}$. Least-squares fitting of a split-Pearson function to the asymmetric profile clearly shows (Fig. 2) that the shoulder is due to the

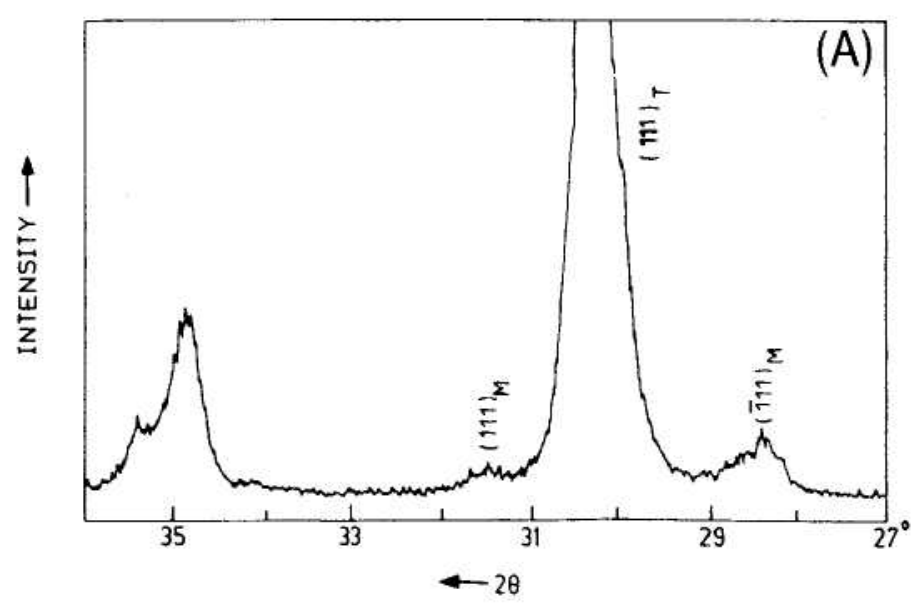

(B)

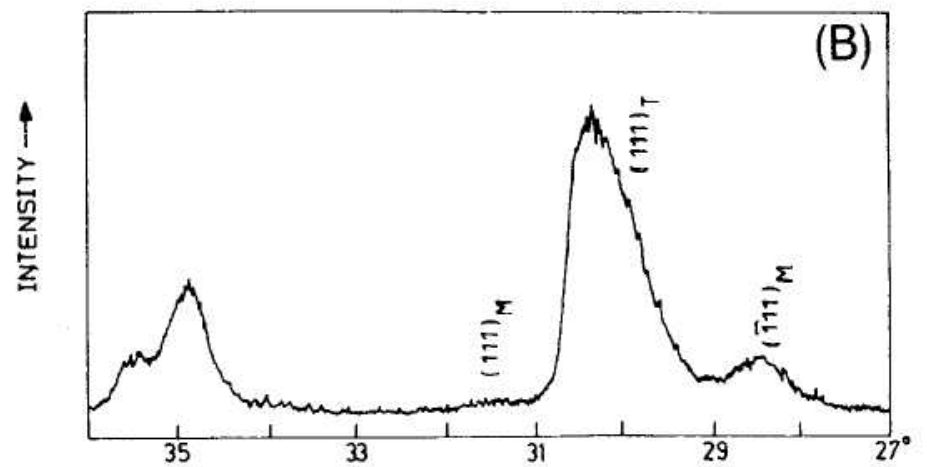


introduction of a new reflection, partially overlapping with (III), on the low-angle side. The new reflection at $2 \theta=29.8^{\circ}$ $(d=0.300 \mathrm{~nm})$ is distinct and does not match with the available XRD data on the $1-\mathrm{ZrO}, m-\mathrm{ZrO}$, or $o-\mathrm{ZrO}$, phases. ${ }^{7-4} \mathrm{We}$ therefore attribute it to a new phase $X(x-\mathrm{ZrO})$. XRD patterns beyond $2 \theta=30^{\circ}$ do not lead to an unambiguous identification of this phase or clarify the existence of any long-range order. The observed $2 \theta$ value of the new reflection is, however, closer to $(111)_{1}$ than $t(1)(11)_{\mathrm{M}}$. This feature suggests the possibility of the $x-\mathrm{ZrO}_{2}$ phase being intermediate in structure between $t-\mathrm{ZrO}_{2}$ and $m-\mathrm{ZrO}$. Further, the serrated appearance of the shoulder in Fig. 1(B) suggests that $x-\mathrm{ZrO}_{2}$ may be characterized by varying concentrations of crystallographic planes with slightly differing $d$-values. Thus the $x-2 \mathrm{rO}_{2}$ phase appears to be ill-defined.

It is interesting to note that another mechanical process, indentation, which involves high hydrostatic stresses, induces the $t \rightarrow m$ transformation in TZP." Cutting, in contrast, induces stresses which have a large shear component. The present evidence therefore suggests that the $t \rightarrow x$ transformation is favored by shear stresses.

XRD data from cut and etched samples (Figs. 3(A), (B), and (C)) show that etching reduces the amount of $x-\mathrm{ZrO}$, and increases the $m-\mathrm{ZrO}_{2}$ content. The gradual decrease in the amount of $x-\mathrm{ZrO}$, and increase in the amount of $m-\mathrm{ZrO}_{2}$ with etching time may be due to the layer-by-layer removal of $x-\mathrm{ZrO}_{2}$ and the increasing exposure of the underlying $t-\mathrm{ZrO}_{2}$ to the acid, leading to $t \rightarrow m$ transformation. Etching with hot sulfuric acid is known to induce the $t \rightarrow m$ transformation. "It is also possible, as suggested by the coexistence of $x-\mathrm{ZrO}_{2}$ and $m-\mathrm{ZrO}_{2}$

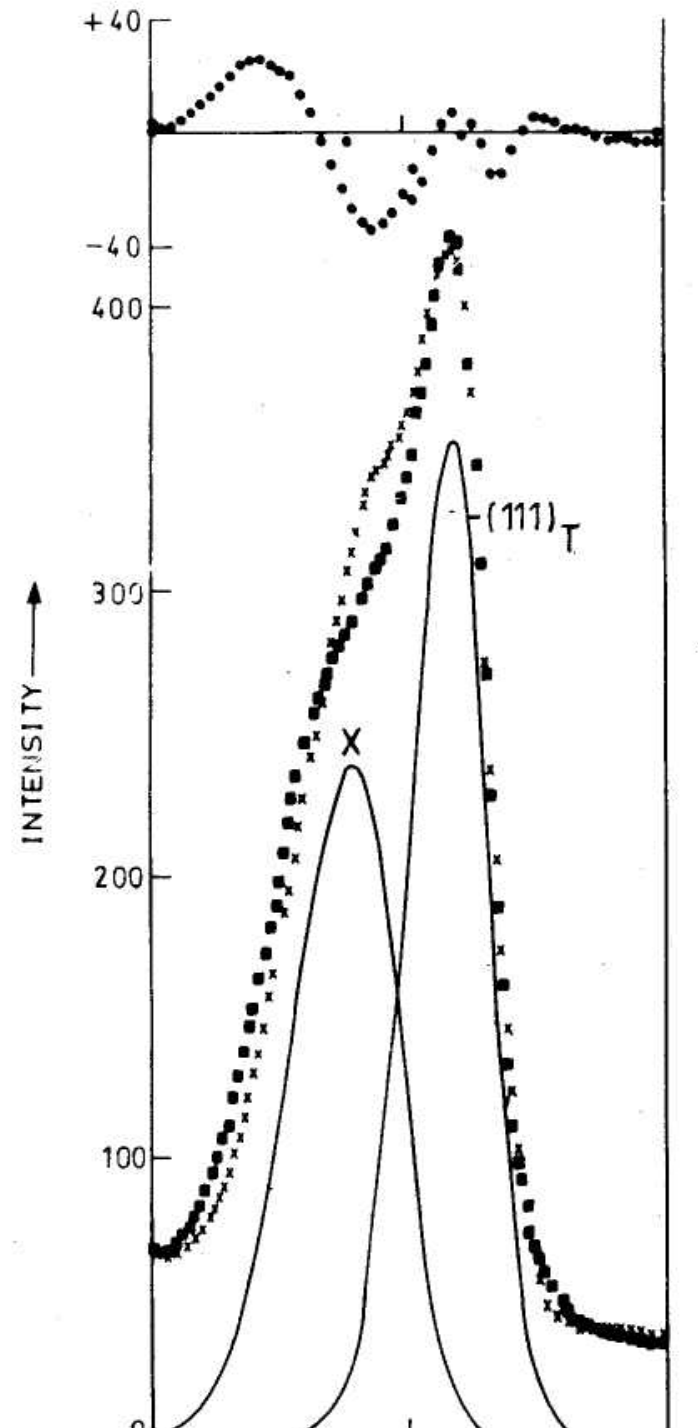

on the lightly etched cut surface (Fig. 3(A)), that the $x-\mathrm{ZrO}$, is transforming directly to $m-\mathrm{ZrO}_{2}$. This issue is not yet resolved

Scanning electron micrographs of the cut surface (Fig. 4(A)) show parallel cutting marks interrupted by pits. The pits may be due to pull-out of transformed grains during cutting. ${ }^{4}$ As cutting does not induce any significant amount of $t \rightarrow m$ transformation (compare Figs. 1(A) and (B)), the pits (Fig. 4(A)) may be pockets where $t \rightarrow x$ transformation has occurred. Figure $4(B)$ shows the pits on the cut surface to become more numerous with etching. After prolonged (3-min) etching, these pits merge with each other to yield a granular surface. Thus, the morphology of the surface suggests that regardless of whether the transformation is $t \rightarrow x$ or $t \rightarrow m$, the associated feature is pitting due to the localized volume changes.

When a cut surface containing $x-\mathrm{ZrO}_{2}$ is indented, the phase assemblage does not change significantly. Polishing the cut surface also did not induce either $t \rightarrow m$ or $x \rightarrow m$ transformation. Srinivasan et al. ${ }^{12}$ report the inhibition of $t \rightarrow m$ transformation induced by the presence of sulfate ions on the surface. In this study, the $x-\mathrm{ZrO}_{2}$ phase may play a similar role.

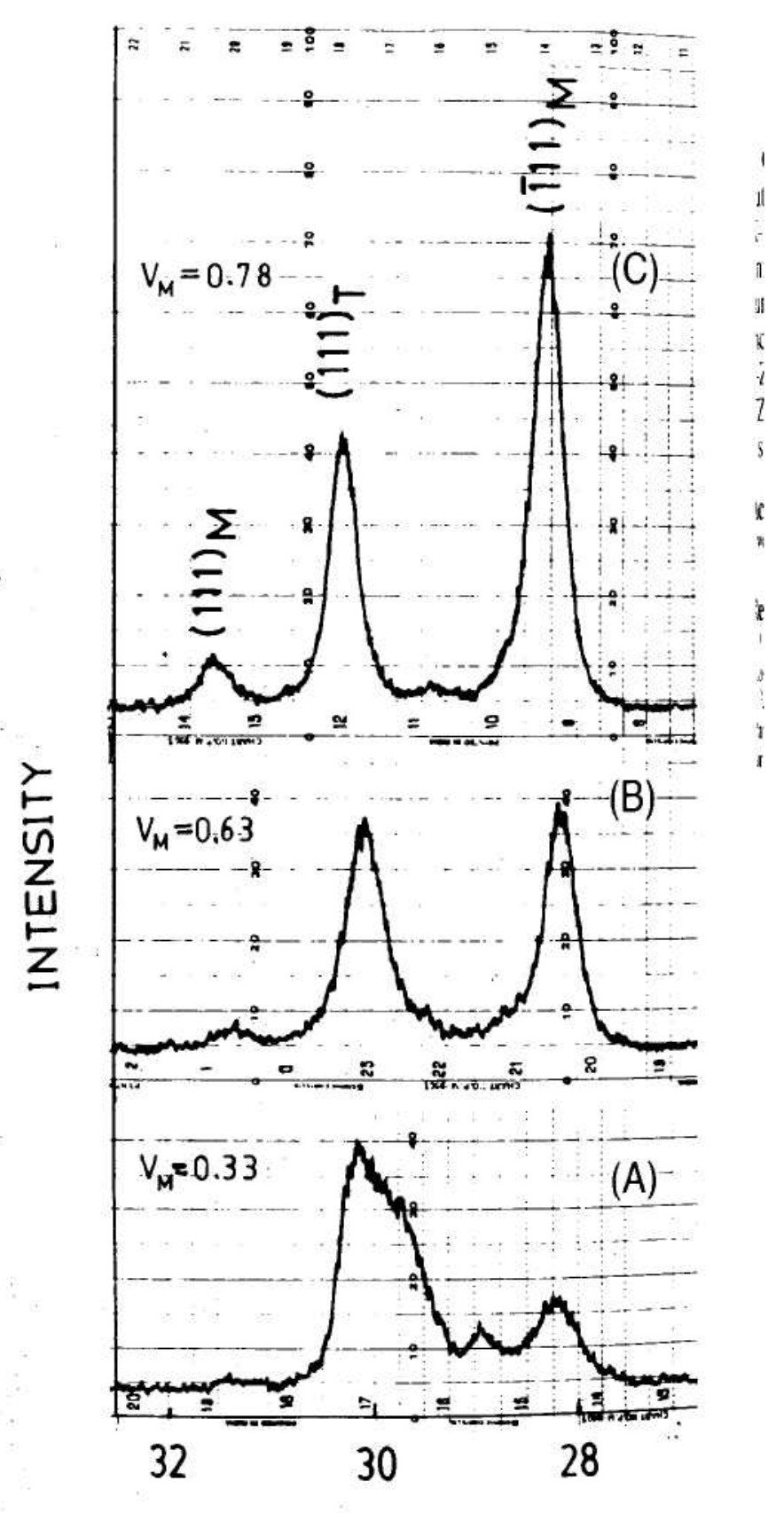




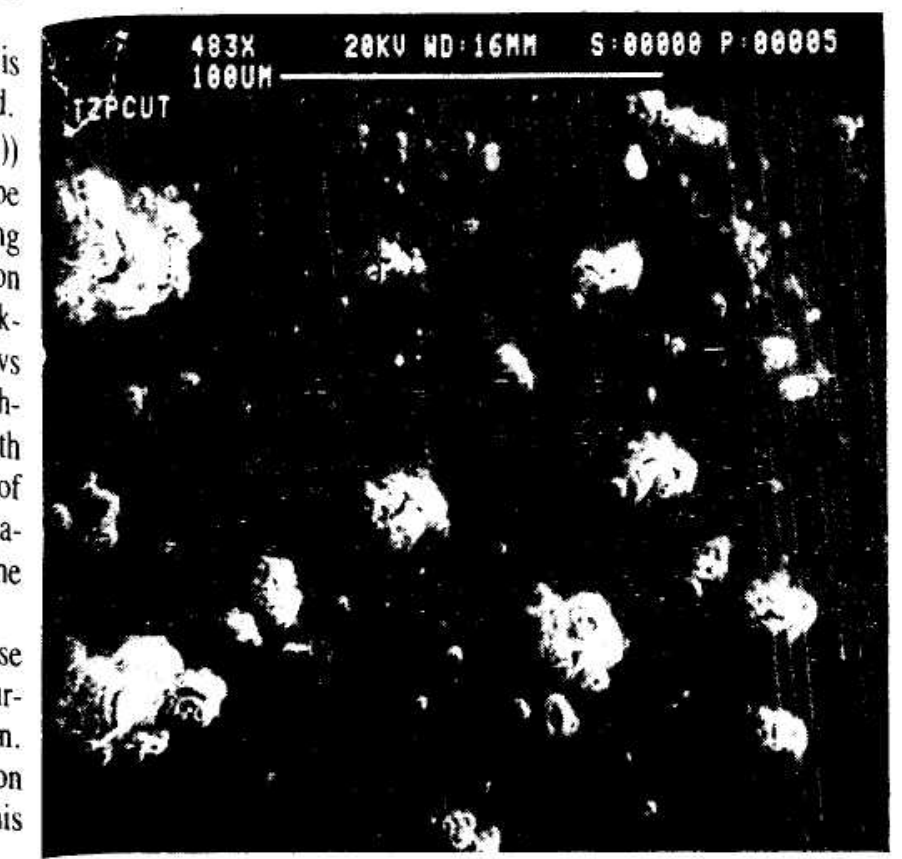

(A)

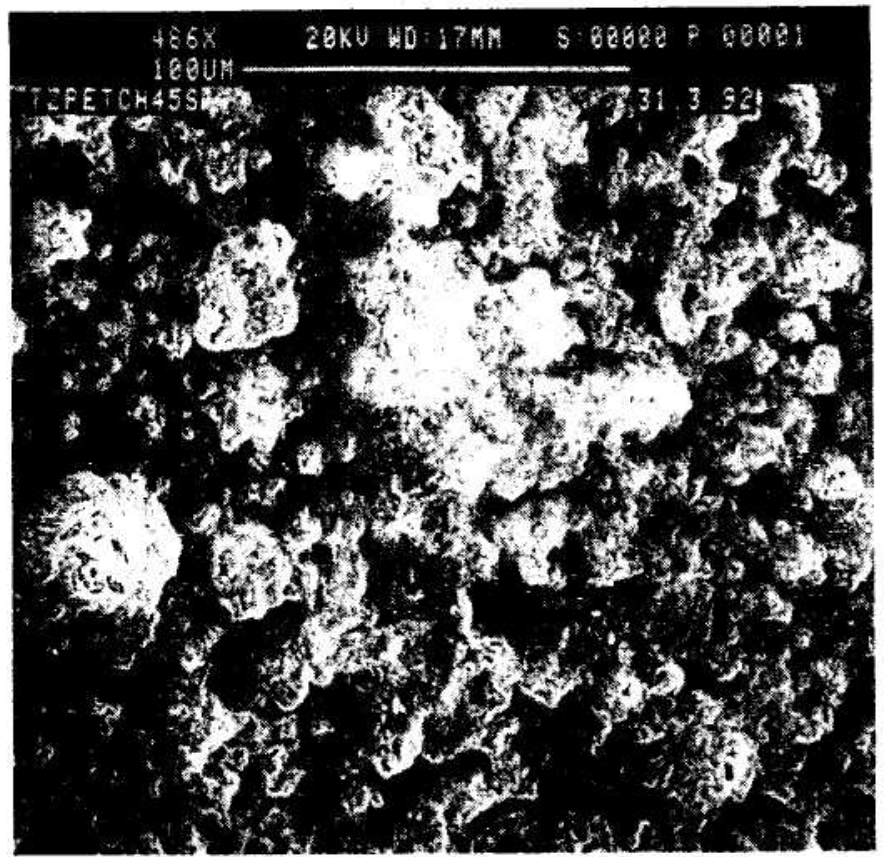

(B)

Fig. 4. Scanning electron micrographs of (A) cut surface (B) cut surface etched for $45 \mathrm{~s}$.

\section{Conclusions}

Commercial 3 Y-TZP rods containing $\approx 20 \% \mathrm{~m}$ - $\mathrm{ZrO}$, were tt using a low-speed diamond saw. Cutting introduces a new ray reflection with $d=0.300 \mathrm{~nm}$, proposed to arise from an nidentified polymorph, $x-\mathrm{ZrO}_{2}$. Indenting or polishing the cut uface sustains the $x-\mathrm{ZrO}_{2}$ phase without any significant xrease in the monoclinic volume fraction $v_{\mathrm{M}}$. Thus, the $\mathrm{ZrO}_{2}$ seems to act as a barrier to further transformation of the ZP. However, with etching, the $x-\mathrm{ZrO}_{2}$ phase disappears, with simultaneous increase in $m-\mathrm{ZrO}_{2}$ content.

knowledgments: The authors acknowledge the valuable assistance en by Ms. H. V. Parimala, Dr. S. C. Balasingh, and Dr. S. Usha Devi.

\section{ieferences}

'R. C. Garyie, R. H. J. Hannink, and R. T. Pascoe, "Ceramic Steel'?," Nature andon), 258, 703-704 (1975).

S. Schmauder and H. Schubert, "Significance of Internal Stresses for the stensitic Transformation in Yttria-Stabilized Tetragonal Zirconia Polycrystals ring Degradation," J. Am. Ceram. Soc., 69 [7] 534-40 (1986).
G. M. Wolten. "Diffusionless Phase Transformations in Zirconia and Hafnia." J. Am. Ceram. Soc., 46, 4I8-22 (1963)

${ }^{4} \mathrm{~N}$. Nakanishi and T. Shigematsu, "Bainite-like Transformation in Zirconia Ceramics," Mater. Trans., JiM, 32 [8] 778-84 (1991).

${ }^{4}$ R. C. Garvie and P. S. Nicholson, "Phase Analysis in Zirconia Systems," J. Am. Ceram. Soc.. 55 [6] 302-305 (1972).

${ }^{6} \mathrm{G}$. Teufer, "The Crystal Structure of Tetragonal ZrO,," Acta Crystallogr., 15, $1187 .(1962)$

${ }^{7}$ Powder Diffraction File (Inorg), Card No. 17-923m. Joint Committee on Powder Diffraction Standards, Swarthmore. PA, 1974.

${ }^{x}$ Powder Diffraction File (Inorg), Card No. 36-420. Joint Committee on Powder Diffraction Standards, Swarthmore, PA, 1990.

${ }^{4}$ D. B. Marshall, M. R. James, and J. R. Porter, "Structural and Mechanical Property Changes in Toughened Magnesia-Partially-Stabilized Zirconia at Low Temperature," J. Am. Ceram. Soc., 72 [2] 218-27 (1989).

"M. J. Reece, P. L. Tetlow, and C. Galiotis, "Phase Transformation around Indentations in Zirconia,"J. Mater. Sci. Lett., 11, 575-77 (1992).

"K. Nakajima, K. Kobayashi, and Y. Murata, "Phase Stability of Y.PSZ in Aqueous Solutions"; pp. 399-407 in Advances in Ceramics, Vol. 12, Science and Terhnology of Zirconia II. Edited by N. Claussen, M. Ruhle, and A. H. Heuer. American Ceramic Society, Columbus, $\mathrm{OH}, 1984$

'R. S. Srinivasan, B. H. Davis, O. B. Cavin, and C. R. Hubbard, "Crystallization and Phase Transformation Process in Zirconia: An in Situ High-Temperature X-ray Diffraction Study," J. Am. Ceram. Soc., 75 [5] 1217-22 (1992). 